\title{
LIPOFILLING OPPORTUNITIES IN BREAST CANCER SURGERY
}

\author{
Igor Motuzyuk \\ Department of Oncology \\ Bogomolets National Medical University \\ 13 Shevchenko blvd., Kyiv, Ukraine, 01601 \\ 180978igor@gmail.com \\ Oleg Sydorchuk \\ Department of Oncology \\ Bogomolets National Medical University \\ 13 Shevchenko blvd., Kyiv, Ukraine, 01601 \\ oleg.sydorchuk0@gmail.com \\ Yevhenii Kostiuchenko \\ Department of Oncology \\ Bogomolets National Medical University \\ 13 Shevchenko blvd., Kyiv, Ukraine, 01601 \\ yekostiuchenko@gmail.com \\ Ivan Smolanka \\ Department of Breast Cancer and its' Reconstructive Surgery \\ National Cancer Institute \\ 33/43 Lomonosova str., Kyiv, Ukraine, 03022 \\ iismolanka@gmail.com
}

\section{Abstract}

In this article the authors described the experience of lipofilling usage at the National Cancer Institute.

Aim of this work was to improve the aesthetic results of surgical treatment of breast cancer patients by the usage of lipofilling in patients after breast reconstruction. The description of methods of lipofilling and their application in cancer patients, the benefits of usage of LipiVage ${ }^{\circledR}$ system was performed.

Materials and methods. The study included 42 women with breast cancer, who received special treatment in 2012-2016. The main group included 21 patients that have received special treatment and undergone lipofilling. The control group included 21 patients, who received only special treatment, (with no lipofilling). Different objective and subjective criteria for evaluating the effectiveness of lipofilling in achieving a satisfactory aesthetic result in patients, who underwent radical and reconstructive surgery for breast cancer, were used in this investigation.

Results shows that the implementation of lipofilling improves the aesthetic perception after breast reconstruction in $20 \%$ of patients, decreases the number of complications after reconstructive operations and are not accompanied by a worsening of results of special treatment in breast cancer patients.

In conclusion it can be noted that our results show a high efficiency of lipofilling after special treatment, its safety and advisability for further usage.

Keywords: lipofilling, breast cancer, breast reconstruction.

\section{Introduction}

Nowadays, there is an important role of reconstructive surgery in breast cancer complex treatment. Lipofilling is one of the modern methods of reconstructive surgery that aims to recover shape, volume, contours of breasts, eliminate defects and asymmetry after special surgical treatment. Technically this is a transplantation of patients' own fat from different areas (with sufficient reserve of fat) to the breast in the required quantity. Lipofilling is a mini-invasive and low-traumatic method which is being used more and more often nowadays in routine clinical practice for breasts reconstruction [1-7]. 
The key principle in the technique of proper lipofilling performance is atraumatic transplantation of intact adipocytes so that to provide the highest survival of cells after the procedure. Cells damage during lipofilling causes resorbtion effect, fat doesn't stay in a breast leading to a need for repeated sessions of lipofilling. Lipofilling is mostly performed under general anesthesia. Technically, lipofilling procedure has 3 stages: liposuction (fat intake) lipoprocessing (fat processing) and lipoinjections (fat input). The most frequent donor site for fat intake is abdomen, because it contains the largest deposit of fat in the human body. Moreover, there is no need to change patient's position on the operating table. However, other areas could be chosen individually for each patient: inner thighs, buttocks area, contrlateral breast etc. Pressure for liposuction performance should be less than $375 \mathrm{~mm} \mathrm{Hg}$ so that to minimize adipocytes damage. To compare, a standard liposuction machine creates negative pressure around $1 \mathrm{~atm}$. (760 $\mathrm{mm} \mathrm{Hg}$ ), the same pressure also could be achieved with a syringe. The size of holes in cannula for fat intake should be the same as the size of the holes in the cannula for lipoinjections so that to maximize efficiency of the procedure (cells flow) and minimize cells damage. The second stage - lipoprocessing is performed to remove blood and any other wastes so that to increase the concentration of clear adipocytes. This leads to better survival of cells and thus durable volume retention after the procedure. There are several methods of lipoprocessing - centrifugation, washing, rinsing, deposition and others. Some surgeons do not carry out any fat processing. In the Department of Breast Cancer and its' Reconstructive Surgery of National Cancer Institute we use LipiVage ${ }^{\circledR}$ system, which automatically performs filtering and concentration of fat during its intake. This disposable system has several advantages comparing to other methods of lipofilling. First of all, eliminating the need for any additional fat processing there is no time lost, while there is evidence in decrease of adipocytes survival with time. In addition to this, there is no contact of fat with the environment, while there is a negative impact of oxygen on adipocytes if other methods of lipoprocessing are performed. Furthermore, there are no any other negative physical or chemical factors that could lead to cells damage and reduction of their survival. Thus, this system is the most conducive for maximum retention of fat after transplantation and minimum risk of complications $[1,8]$. The third stage - lipoinjections - is an input of an individual volume of fat to the breast. The volume depends on the surgery aim, the number of planned sessions, physiological features etc. In addition, during the input of cannula for lipoinjections to a necessary area, a surgeon mechanically breaks down adhesions formed between skin and breast implant, which often occur in one-step mastectomy with prepectoral implant-based breast reconstruction. In this case, patients do not develop animation deformities during pectoral muscle tension. This also reduces the risk of such a quite frequent complication as capsular contracture (Fig. 1). The same positive effect is observed with subpectoral implant-based reconstruction. During the third stage of lipofilling surgeons destroy adhesions between the pectoral muscle and implant, respectively [9-11].

In this article the aim of our work was to improve direct results of breast cancer treatment. The research is performed at the Department of Oncology, Bogomolets National Medical University at the base of the Department of Breast Cancer and its' Reconstructive Surgery of National Cancer Institute.

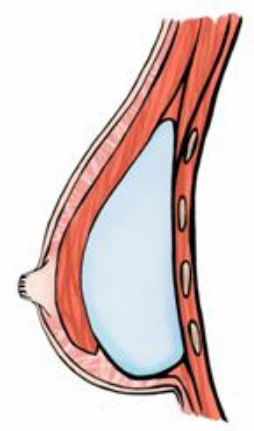

$a$

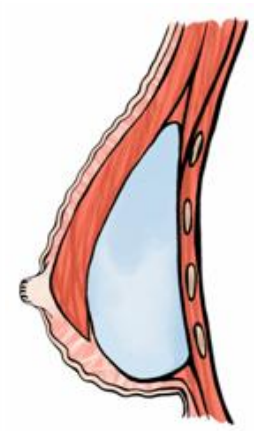

$b$

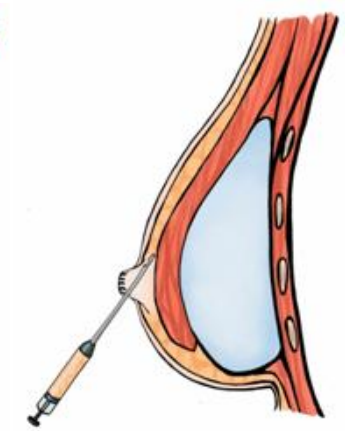

C

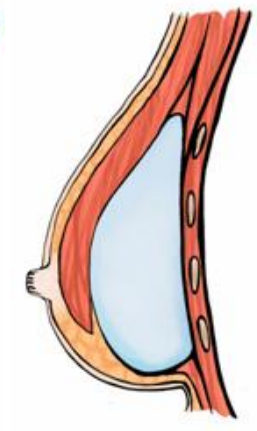

$d$

Fig. 1. The use of lipofilling in the treatment of animation symptom: $a$-there are adhesions between skin and breast implant; $b$ - there are animation deformities during pectoral muscle straining; $c$-during the third stage of lipofilling a surgeon inputs fat and at the same time destroys adhesions; $d$-after lipofilling there are no animation deformities during pectoral muscle tension 


\section{Aim of research}

The aim of this work was to improve the aesthetic results of surgical treatment of breast cancer patients by the usage of lipofilling in patients after breast reconstruction.

\section{Materials and methods}

The study includes 42 women with breast cancer $\left(\mathrm{pT}_{1-3} \mathrm{~N}_{1-2} \mathrm{M}_{0}\right)$, who received special treatment in 2012-2016. The average age of patients was 49,5 $\pm 10,9$ years. The main group includes 21 patients that have received special treatment and undergone lipofilling. The control group includes 21 patients, who received only special treatment, - it was subcutaneous mastectomy with round implant prosthetics (with no lipofilling). In the main group lipofilling was held as the final stage of breast reconstruction after the following breast cancer surgeries: subcutaneous mastectomy with one-step round implant prosthetics - 16 (76,2 \%), mastectomy with one-step TDL breast reconstruction - 2 (9,5\%), mastectomy with one-step TRAM breast reconstruction - $3(14,3 \%)$. Each patient had $1,86 \pm 0,65$ sessions of lipofilling ( 1 to 3 sessions). Average transplanted volume was 105,2 $\pm 50,26 \mathrm{ml}$ (minimum $60 \mathrm{ml}, 250 \mathrm{ml}$ maximum). The median of lipofilling performance was in 12 months after special surgical treatment. For lipofilling conduction patients were in the hospital for one day. Follow-up median was 20 months.

To assess the efficiency of lipofilling in the National Cancer Institute clinic we made a survey of patients in 3 months after lipofilling in the main group and at the analogical time in the control group. Lipofilling efficiency was evaluated in general and by special parameters. These parameters are breast resilience, volume, shape, skin elasticity, skin turgor, absence of deformations and symmetry of breasts. In the questioning a 5-point scale was used: 5 - very good, 4 - good, 3 - satisfactory, 2 - bad, 1 - very bad. The significance of the difference between the state of these parameters in points before and in 3 moths after lipofilling holding was evaluated using Student's $t$-test.

After that, every patient was evaluated with a LENT-SOMA scale. This scale includes a subjective parameter - pain, and four objective parameters - telangiectasia, edema, fibrosis and atrophy $[1,3]$. These parameters were estimated in the following way (Table 1).

Table 1

LENT-SOMA scale

\begin{tabular}{ccccc}
\hline Points & $\mathbf{1}$ & \multicolumn{2}{c}{$\mathbf{3}$} & $\mathbf{4}$ \\
\hline \multirow{2}{*}{ Pain } & $\begin{array}{c}\text { Periodic and minimum } \\
\text { hypersensitivity, itching }\end{array}$ & $\begin{array}{c}\text { Periodic and } \\
\text { tolerant pain }\end{array}$ & Constant and intensive pain & $\begin{array}{c}\text { Unbearable pain, } \\
\text { poorly treated }\end{array}$ \\
\hline Teleangiectasia & $<1 \mathrm{~cm}^{2}$ & Objective parameters of LENT-SOMA scale & $>4 \mathrm{~cm}^{2}$ \\
Edema & Asymptomatic & $1-4 \mathrm{~cm}^{2}$ & Symptomatic \\
Atrophy & $10-25 \%$ & $>25-40 \%$ & Secondary dysfunction \\
Fibrosis & $\begin{array}{c}\text { Increased density, barely } \\
\text { palpable }\end{array}$ & $\begin{array}{c}\text { Certain increase in } \\
\text { density and hardness }\end{array}$ & $\begin{array}{c}\text { Highly expressed density, retrac- } \\
\text { tion, fixation }\end{array}$ & Full breast
\end{tabular}

The significance of the difference between LENT-SOMA scale parameters state (in points) before and in 3 moths after lipofilling holding was also evaluated using Student's $t$-test.

Safety assessment was conducted by the appearance of complications or disease progression after lipofilling performance during the observation period.

\section{Results of research}

According to the survey replies, in the main group most patients rated their breast condition as good - $12(57 \%)$; very good - $3(14 \%)$, satisfactory - $6(29 \%)$. None of the patients assessed the state of breast as bad or very bad (Fig. 2). In the control group, 9 patients (43\%) rated their condition as good, $8(38 \%)$ - as satisfactory, $3(14 \%)$ - as bad and $1(5 \%)$ - as very bad. None of the patients in the control group gave an answer "very good" (Fig. 3). In addition to that, patients 
of the main group were asked a question on how do they assess breast condition after lipofilling undergoing, compared to the state before it is held. A reply "better" gave 14 patients (67\%), "much better" - $4(19 \%)$ and "same" - $3(14 \%)$. There were no patients who experienced worsening of their breast state (Fig. 4).

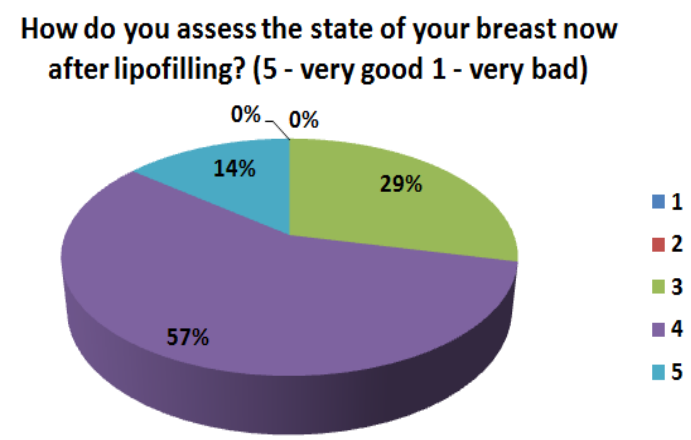

Fig. 2. Main group patients' evaluation of their breast state in 3 months after lipofilling

How do you assess the state of your breast now
(with no lipofilling)? (5 - very good 1 - very bad)

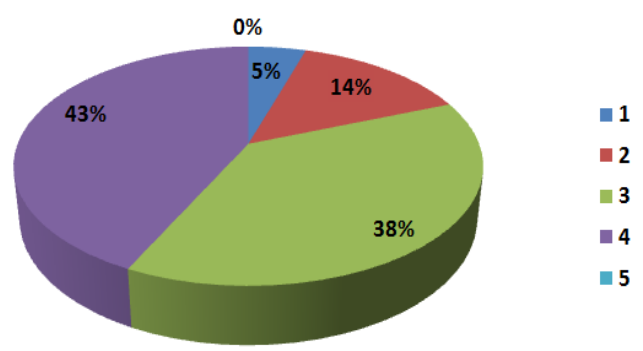

Fig. 3. Control group patients' evaluation of their breast state
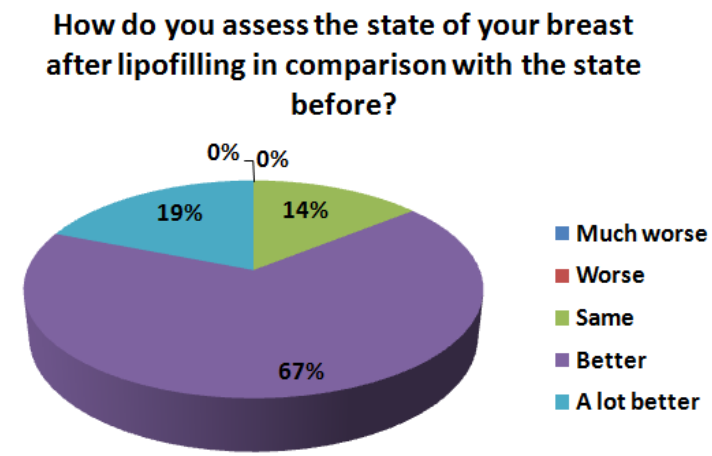

Fig. 4. Main group patients' evaluation of their breast state in comparison with the state before lipofilling

Table 2 represents questioning results of main group patients by specific parameters. The table shows that in 3 months after lipofilling, patients experienced significant improvement of all these parameters. There was an improvement of breasts resilience (score on a 5-point scale before was $2,24 \pm 0,7$, and after it was $3,62 \pm 0,74, \mathrm{p}<0,01$ ), volume (before $1,95 \pm 0,74$, after $3,81 \pm 0,87, \mathrm{p}<0,01$ ),

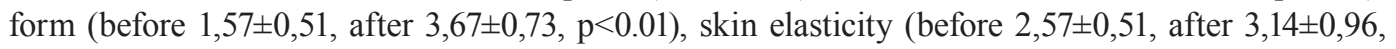
$\mathrm{p}<0,05$ ), skin turgor (before $1,86 \pm 0,73$ after $3,38 \pm 0,86, \mathrm{p}<0,01$ ), absence of defects (before $2,05 \pm 0,8$, after $3,29 \pm 0,85, \mathrm{p}<0,01$ ), and symmetry of breasts (before $1,62 \pm 0,59$, after $3,76 \pm 0,94, p<0,01$ ).

The results of patients' functional assessment with LENT-SOMA scale are shown in Table 3. There we can see a significant decrease of pain intensity (before $0,95 \pm 0,8$, after $0,52 \pm 0,51, \mathrm{p}<0,05$ ), teleangiectasia (before $1,14 \pm 0,79$, after $0,71 \pm 0,56, \mathrm{p}<0,05$ ), atrophy (before 
$1,81 \pm 0,93$, after $1,1 \pm 0,89, \mathrm{p}<0,05$ ), edema (before $1,48 \pm 0,87$, after $0,95 \pm 0,8, \mathrm{p}<0,05$ ) and fibrosis (before $2,05 \pm 0,97$, after $1,48 \pm 0,75, \mathrm{p}<0,05$ ).

Table 2

Questioning results of the main group patients

\begin{tabular}{lcccc}
\hline & Parameter & Before lipofilling, points & 3 months after lipofilling, points & p \\
\hline 1 & Resilience & $2,24 \pm 0,7$ & $3,62 \pm 0,74$ & $<0,01$ \\
2 & Volume & $1,95 \pm 0,74$ & $3,81 \pm 0,87$ & $<0,01$ \\
3 & Shape & $1,57 \pm 0,51$ & $3,67 \pm 0,73$ & $<0,01$ \\
4 & Skin elasticity & $2,57 \pm 0,51$ & $3,14 \pm 0,96$ & $<0,05$ \\
5 & Skin turgor & $1,86 \pm 0,73$ & $3,38 \pm 0,86$ & $<0,01$ \\
6 & Absence of deformations & $2,05 \pm 0,8$ & $3,29 \pm 0,85$ & $<0,01$ \\
7 & Symmetry of breasts & $1,62 \pm 0,59$ & $3,76 \pm 0,94$ & $<0,01$
\end{tabular}

Table 3

LENT-SOMA scale evaluation results of the main group patients

\begin{tabular}{rcccc}
\hline & Parameter & Before lipofilling, points & 3 months after lipofilling, points & p \\
\hline 1 & Pain & $0,95 \pm 0,8$ & $0,52 \pm 0,51$ & $<0,05$ \\
2 & Teleangiectasia & $1,14 \pm 0,79$ & $0,71 \pm 0,56$ & $<0,05$ \\
3 & Atrophy & $1,81 \pm 0,93$ & $1,1 \pm 0,89$ & $<0,05$ \\
4 & Edema & $1,48 \pm 0,87$ & $0,95 \pm 0,8$ & $<0,05$ \\
5 & Fibrosis & $2,05 \pm 0,97$ & $1,48 \pm 0,75$ & $<0,05$
\end{tabular}

There were no complications or locoregional recurrences in the main group patients during the observation period, while in the control group there was one case of capsular contracture. Thus, the rate of complications in the study group was $0 \%$, and in the control group this rate was $5 \%$.

\section{Discussion of results}

According to subjective estimates of the patients lipofilling significantly increased the percentage of patients satisfied with the aesthetic result of surgical treatment. We observed a statistically significant difference between the groups of patients' perception of elasticity, volume and shape of the breasts, elasticity and turgor of their skin, absence of defects and symmetry. Fat grafting significantly reduced the number of complications after breast reconstruction (edema, fibrosis, atrophy of the skin, telangiectasia, pain). We believe lipofillig is an ideal tool for elimination the symptom of the animation after breast reconstruction with implant. Most likely, this is not only a mechanical separation of the skin from the scar, thickening of the subcutaneous layer, but also the active influence of the proteolytic enzymes, which makes the breast more natural. Almost fat grafting was a universal procedure to correct minor deformities and asymmetries of the breasts that is difficult to correct by other methods. In addition, it does not have the complications that occur with other methods of correction of breasts. It should also be noted that this procedure did not worsen the long-term results of treatment of patients with breast cancer and was not accompanied by complications.

These results indicate lipofilling's safety, however, further long-term follow-up is for sure required. The literature data also show a low incidence of complications or locoregional recurrences. The most common complications are liponecrosis, oleogranulomas, calcifications, cysts formation, infections, insufficient or excessive correction. Less frequent complications are implant damage, pneumothorax, intravascular injection with embolism. There are also doubts concerning an interaction between transplanted fat and tumor cells [12-22]. 


\section{Conclusions}

Lipofilling is successfully used as a final stage of breast cancer reconstructive surgery. This is a mini-invasive, low-impact, effective and safe method. Lipofilling provides thorough removal of tissue defects, asymmetry or other disadvantages after special surgical treatment, improves the quality of patients' life. Lipofilling does not require a long-term stay of a patient in a hospital (1 day). This method does not affect the main disease process. Lipofilling prevents capsular contracture development after subcutaneous mastectomy with implant prosthetics.

\section{References}

[1] Smolanka, I. I., Motuziuk, I. N., Sydorchuk, O. I., Kostyuchenko, Ye. V., Ligirda, O. F., Dosenko, I. V. et. al. (2015). Place of lipofiling in complex treatment of patients with the breast cancer: history aspects and own experience. Clinical oncology, 2015 No 3 (19): 40-44.

[2] Vallejo, A., Urban, C., Zucca-Matthes, G., Rietjens, M. (2013). Is There Enough Evidence to Use Lipofilling in Breast Cancer Reconstruction? Plastic and Reconstructive Surgery, 132 (4), 689e-691e. doi: 10.1097/ prs.0b013e31829fe40e

[3] Hamza, A., Lohsiriwat, V., Rietjens, M. (2013). Lipofilling in breast cancer surgery. Gland Surgery, 2 (1), 7-14. doi: 10.3978/j.issn.2227-684X.2013.02.03

[4] Illouz, Y. G., Sterodimas, A. (2009). Autologous Fat Transplantation to the Breast: A Personal Technique with 25 Years of Experience. Aesthetic Plastic Surgery, 33 (5), 706-715. doi: 10.1007/s00266009-9377-1

[5] Schultz, I., Lindegren, A., Wickman, M. (2012). Improved shape and consistency after lipofilling of the breast: patients' evaluation of the outcome. Journal of Plastic Surgery and Hand Surger, 46 (2), 85-90. doi: 10.3109/2000656x.2011.653256

[6] Chan, C. W. (2016). Considerations regarding lipofilling in patients after breast cancer. Journal of Plastic, Reconstructive \& Aesthetic Surgery, 69 (5), e103-e104. doi: 10.1016/j.bjps.2016.01.016

[7] Kasem, A., Wazir, U., Headon, H., Mokbel, K. (2015). Breast Lipofilling: A Review of Current Practice. Archives of Plastic Surgery, 42 (2), 126. doi: 10.5999/aps.2015.42.2.126

[8] Genesis Biosystems. Available at: http://genesisbiosystems.com/products/lipivage/

[9] Becker, H., Lind, J. G., Hopkins, E. G. (2015). Immediate Implant-based Prepectoral Breast Reconstruction Using a Vertical Incision. Plastic and Reconstructive Surgery - Global Open, 3 (6), e412. doi: $10.1097 /$ gox.0000000000000384

[10] Hammond, D. C., Schmitt, W. P., O’Connor, E. A. (2015). Treatment of Breast Animation Deformity in Implant-Based Reconstruction with Pocket Change to the Subcutaneous Position. Plastic and Reconstructive Surgery, 135 (6), 1540-1544. doi: 10.1097/prs.0000000000001277

[11] Bracaglia, R., Tambasco, D., Gentileschi, S., D’Ettorre, M. (2013). Triple-Plane Technique for Breast Augmentation: Solving Animation Deformities. Aesthetic Plastic Surgery, 37 (4), 715-718. doi: 10.1007/s00266-013-0128-y

[12] Semprini, G., Cattin, F., Zanin, C. et. al. (2014). About locoregional reccurence risk after lipofilling in breast cancer patients: our experience. Minerva Chir., 69 (2), 91-96.

[13] Petit, J. Y., Lohsiriwat, V., Clough, K. B., Sarfati, I., Ihrai, T., Rietjens, M. et. al. (2011). The Oncologic Outcome and Immediate Surgical Complications of Lipofilling in Breast Cancer Patients: A Multicenter Study-Milan-Paris-Lyon Experience of 646 Lipofilling Procedures. Plastic and Reconstructive Surgery, 128 (2), 341-346. doi: 10.1097/prs.0b013e31821e713c

[14] Petit, J. Y., Botteri, E., Lohsiriwat, V., Rietjens, M., De Lorenzi, F., Garusi, C. et. al. (2011). Locoregional recurrence risk after lipofilling in breast cancer patients. Annals of Oncology, 23 (3), 582-588. doi: 10.1093/annonc/mdr158

[15] Riggio, E., Bordoni, D., Nava, M. B. (2013). Oncologic Surveillance of Breast Cancer Patients After Lipofilling. Aesthetic Plastic Surgery, 37 (4), 728-735. doi: 10.1007/s00266-013-0166-5

[16] Lohsiriwat, V., Curigliano, G., Rietjens, M., Goldhirsch, A., Petit, J. Y. (2011). Autologous fat transplantation in patients with breast cancer: "silencing" or "fueling" cancer recurrence? The Breast, 20 (4), 351-357. doi: 10.1016/j.breast.2011.01.003 
[17] Semprini, G., Cattin, F., Lazzaro, L., Cedolini, C., Parodi, P. C. (2012). About locoregional recurrence risk after lipofilling in breast cancer patients. Annals of Oncology, 23 (3), 802-803. doi: 10.1093/ annonc/mdr632

[18] Silva-Vergara, C., Fontdevila, J., Descarrega, J., Burdio, F., Yoon, T.-S., Grande, L. (2016). Oncological outcomes of lipofilling breast reconstruction: 195 consecutive cases and literature review. Journal of Plastic, Reconstructive \& Aesthetic Surgery, 69 (4), 475-481. doi: 10.1016/j.bjps.2015.12.029

[19] Kronowitz, S. J., Mandujano, C. C., Liu, J., Kuerer, H. M., Smith, B., Garvey, P. et. al. (2016). Lipofilling of the Breast Does Not Increase the Risk of Recurrence of Breast Cancer. Plastic and Reconstructive Surgery, 137 (2), 385-393. doi: 10.1097/01.prs.0000475741.32563.50

[20] Massa, M., Gasparini, S., Baldelli, I., Scarabelli, L., Santi, P., Quarto, R., Repaci, E. (2015). Interaction Between Breast Cancer Cells and Adipose Tissue Cells Derived from Fat Grafting. Aesthetic Surgery Journal, 36 (3), 358-363. doi: 10.1093/asj/sjv194

[21] Chirappapha, P., Rietjens, M., De Lorenzi, F., Andrea, M., Hamza, A., Petit, J.-Y. et. al. (2015). Evaluation of Lipofilling Safety in Elderly Patients with Breast Cancer. Plastic and Reconstructive Surgery Global Open, 3 (7), e441. doi: 10.1097/gox.0000000000000411

[22] Petit, J. Y., Maisonneuve, P., Rotmensz, N., Bertolini, F., Clough, K. B., Sarfati, I. et. al. (2015). Safety of Lipofilling in Patients with Breast Cancer. Clinics in Plastic Surgery, 42 (3), 339-344. doi: 10.1016/ j.cps.2015.03.004 